\title{
Fast Responding Hydrogen Gas Sensors using Platinum Nanoparticle Modified Microchannels and Ionic Liquids
}

\author{
Ghulam Hussain $\uparrow,{ }^{1}$ Mengchen $\mathrm{Ge}_{\dagger}{ }^{2}$, Chuan $\mathrm{Zhao}^{2,{ }^{*}}$ and Debbie S. Silvester ${ }^{1, *}$ \\ ${ }^{1}$ Curtin Institute for Functional Molecules and Interfaces, School of Molecular and Life Sciences, Curtin University, GPO Box \\ U1987, Perth, 6845, WA, Australia. \\ ${ }^{2}$ School of Chemistry, Faculty of Science, The University of New South Wales, Sydney 2052, Australia \\ $\dagger$ These authors contributed equally to this work.
}

* Corresponding authors; E-Mail: d.silvester-dean@curtin.edu.au; c.zhao@unsw.edu.au.

KEYWORDS: hydrogen sensing; gas detection; microchannels; room temperature ionic liquids; response time

\begin{abstract}
From a safety perspective, it is vital to have fast responding gas sensors for toxic and explosive gases in the event of a gas leak. Amperometric gas sensors have been developed for such a purpose, but their response times are often relatively slow - on the order of 50 seconds or more. In this work, we have developed sensors for hydrogen gas that demonstrate ultra-fast response times. The sensor consists of an array of gold microchannel electrodes, electrodeposited with platinum nanoparticles (PtNP) to enable hydrogen electroactivity. Very thin layers $(\sim 9 \mu \mathrm{m})$ of room temperature ionic liquids (RTILs) result in an extremely fast response time of only 2 seconds, significantly faster than the other conventional electrodes examined (unmodified Pt electrode, and PtNP modified Au electrode). The RTIL layer in the microchannels is much thinner than the channel length, showing an interesting yet complex diffusion pattern and characteristic thin-layer behavior. At short times (e.g. on the timescale of cyclic voltammetry), the oxidation current is smaller and steady-state in nature, compared to macrodisk electrodes. At longer times (e.g. using long-term chronoamperometry), the diffusion layer is large for all surfaces and extends to the liquid/gas phase boundary, where the gas is continuously replenished from the flowing gas stream. Thus, the current response is the largest on the microchannel electrode, resulting in the highest sensitivity and lowest limit of detection for hydrogen. These microchannel electrodes appear to be highly promising surfaces for the ultrafast detection of hydrogen gas, particularly at relevant concentrations close to, or below, the lower explosive limit of 4 vol- $\% \mathrm{H}_{2}$.
\end{abstract}




\section{INTRODUCTION}

Hydrogen gas is widely used in aeronautic, aerospace, automobile, medical and industrial applications [1-5]. Recently, hydrogen-powered fuel cell vehicles have gained much interest, including hydrogen-powered cars, buses, trucks, submarines, and ships, where hydrogen is combined with oxygen in fuel cells to produce electricity, with only water and heat as by-products [6-8]. Hydrogen is also used as a cryogenic fuel in rockets during aerospace operations, and as a lifting gas in weather balloons [9], whilst finding use in fuel cells and batteries in space stations and satellites [10, 11], In power generation systems, hydrogen is used as a coolant, and it has wide applications in the chemical industry e.g. in the synthesis of ammonia in the Haber-Bosch process and for the production of fertilizers, methanol, cyclohexane and acetic acid [3].

Despite its vast applications, the use and storage of hydrogen presents a handling hazard, since it is explosive in air at $4-75 \%$ by volume [12], where 4 vol-\% is the lower explosive limit (LEL) and 75 vol- $\%$ is the upper explosive limit (UEL). The accidental release of hydrogen has contributed to many disasters, including the Hindenburg disaster in 1937, the Three Mile Island accident in 1979, the Chernobyl accident in 1986, and more recently, the Fukushima nuclear power plant explosion in 2011 that resulted in several deaths and released a large amount of radioactivity with long-term effects on the environment, human, animal and marine life [13-17]. Due to the widespread and potentially hazardous use of hydrogen, there is a continuous need for selective, accurate and fast methods for its detection, particularly at concentrations near the LEL. Early leak warnings could alert the formation of potentially explosive gas/air mixture and thus prevent against explosions or accidents [18]. Different chemical methods have been employed to monitor hydrogen gas such as optical methods, gas chromatography or spectroscopy [19], however, the instruments used for these techniques are often costly, large in size, require high maintenance and have a relatively slow sampling time.

Electrochemical sensors have been used in miniaturized hydrogen sensing devices over the last few decades [18, 20]. Commercially available hydrogen sensors are typically based on solid-state sensing materials [21, 22]. These include noble metal hybrid thin films coupled with micro-electro-mechanical systems (MEMS), where resistance changes are used to detect hydrogen [23]. Sadek et al. reported a conducting polymer based conductometric hydrogen gas sensor where doped and de-doped polyaniline nanofibers were deposited onto a sapphire transducer, to measure the resistance of the sensitive layer upon exposure to hydrogen at room temperature [24]. Gu et al. reviewed hydrogen gas sensors based on semiconductor metal oxide (SMO) thin layer nanostructures that measure the resistance, work function, optical properties, and acoustic waves of the SMO layer when the sensors are exposed to hydrogen gas [25]. These type of sensors are still in the development phase and more research is required to optimize their sensitivity, selectivity, response time, along with their cost, portability, robustness, miniaturization, and their power consumption [25].

Amperometric techniques have also been used to detect hydrogen, as outlined in reviews by Stetter and co-workers, with a range of electrolytes (e.g. liquids, polymers and solids) studied [20,26]. These can be employed in miniaturized devices, with high sensitivity, high selectively, fast response times, low-cost, portability, and the ability to operate at a range of temperatures. The solvent/electrolyte combination used in commercial amperometric sensors is typically a water/sulfuric acid mixture, but this can be prone to evaporation in hot and dry conditions. Room temperature ionic liquids (RTILs) have been proposed as a substitute solvent in 'membrane-free' amperometric gas sensors due to their 
low volatility, intrinsic conductivity, high chemical and physical stability, wide electrochemical windows and good gas solvation properties [27-29]. The electrochemical behavior and oxidation mechanism for hydrogen in RTILs has been well studied by several groups [30-40]. Very fast response times $(<0.1 \mathrm{sec})$ for $\mathrm{H}_{2}$ have recently been reported by Zeng and co-workers [41] in RTILs using porous electrodes based on the Clark-cell design [42]. The gas enters from the back-side of the electrode and diffuses through the porous electrode where it is oxidised in the RTIL media. This ultrafast response is a big benefit for a $\mathrm{H}_{2}$ leak detector, but these Clark-type designs typically require specialised manufacturing and the use of a relative large volume $(\sim 150 \mu \mathrm{L})$ of expensive RTIL electrolyte.

The near-zero volatility of RTILs allows for the application of very thin electrolyte layers, which is believed to result in improved response times. This was demonstrated by Gunawan et al. [43] who employed thin strips of RTILs in the form of microchannel arrays on gold surfaces [43]. These surfaces showed enhanced currents and faster response times for oxygen sensing compared to a conventional macrodisk electrode [43]. Other gases such as hydrogen chloride and ammonia have also been recently detected on these surfaces [44]. However, this technique has so far only been limited to gold surfaces, since hexadecanethiol (HDT) has strong gold-thiol interactions but shows poor adhesion to other electrode surfaces such as platinum or glassy carbon. In the present study, we use gold microchannel electrodes, and modify them with platinum nanoparticles (PtNPs) to detect hydrogen gas, which has very sluggish kinetics on gold surfaces $[30,31]$. We show that this electrode design gives rise to ultra-fast response times, high sensitivity and low limits of detection for hydrogen in RTILs. By depositing different electrocatalysts, we can combine the advantages of the fast mass transport inherent to the microchannel array electrodes, and the fast kinetics of the electrocatalyst, to target different gases that are difficult to detect on gold surfaces. These modified surfaces could be used in the future with miniaturised planar devices and tiny volumes of RTIL solvent to produce low-cost, fast responding and highly sensitive sensors for gases as an alternative to the Clark-cell design. 


\section{MATERIALS AND METHODS}

\subsection{Chemical Reagents}

All chemicals were commercially available and used as received. Ethanol (EtOH, 99 \%, Sigma-Aldrich), acetone (99\%, Sigma-Aldrich), sulfuric acid (98\% w/w [18.4 M], Sigma-Aldrich), chloroplatinic acid hydrate $\left(\mathrm{H}_{2} \mathrm{PtCl}_{6} \cdot \mathrm{xH}_{2} \mathrm{O}\right.$, anhydrous, trace metal basis, $\geq 99.9 \%$, Sigma-Aldrich), and hexadecanethiol (HDT, $99.9 \%$, Sigma-Aldrich) were used as received. The room temperature ionic liquid (RTIL) 1-ethyl-3-methylimidazolium bis(trifluoromethylsulfonyl)imide ([ $\left.\mathrm{C}_{2} \mathrm{mim}\right]\left[\mathrm{NTf}_{2}\right]$ ) was purchased from Merck (Kilsyth, Victoria, Australia) at ultrahigh purity electrochemical grade. Ultrapure water with a resistance of $18.2 \mathrm{M} \Omega . \mathrm{cm}$ was prepared by an ultrapure water purification system (Millipore Pty Ltd., North Ryde, NSW, Australia). Acetone ( $>99.9 \%$, Sigma-Aldrich) was used for rinsing the electrodes before and after use. Ethanol (99\%, Sigma-Aldrich) was used to rinse the HDT printed gold electrode prior to starting gas experiments. Hydrogen gas $(99.99 \%$, high purity) and nitrogen gas ( $\geq 99.99 \%$, high purity for further dilution of $\mathrm{H}_{2}$ ) cylinders were purchased from BOC gases, Welshpool, WA, Australia.

\section{Fabrication of Gold Microchannels with Platinum Nanoparticles}

A gold macrodisk electrode (1.6 mm diameter, BASi, West Lafayette, IN, USA) was employed as the working electrode. After thorough polishing (see next section for details), the gold surface was printed with hexadecanethiol (HDT) using a polydimethyl siloxane (PDMS) stamp to create an array of Au microchannels. Prior to use, the PDMS stamp was washed by sonication in ethanol for 2 minutes. The PDMS stamp was then inked with one drop of $5 \mathrm{mM}$ ethanolic HDT solution for 1 minute (step 1 in Figure 1). Any excess HDT was removed using a lint-free tissue, and the stamp was dried gently under a nitrogen stream for 30 seconds (step 2). The stamp was pressed onto the gold electrode and held for ca. 50 seconds (step 3). After printing, the gold electrode with the micropattern was rinsed twice in ethanol and then dried gently under a nitrogen stream (step 4).

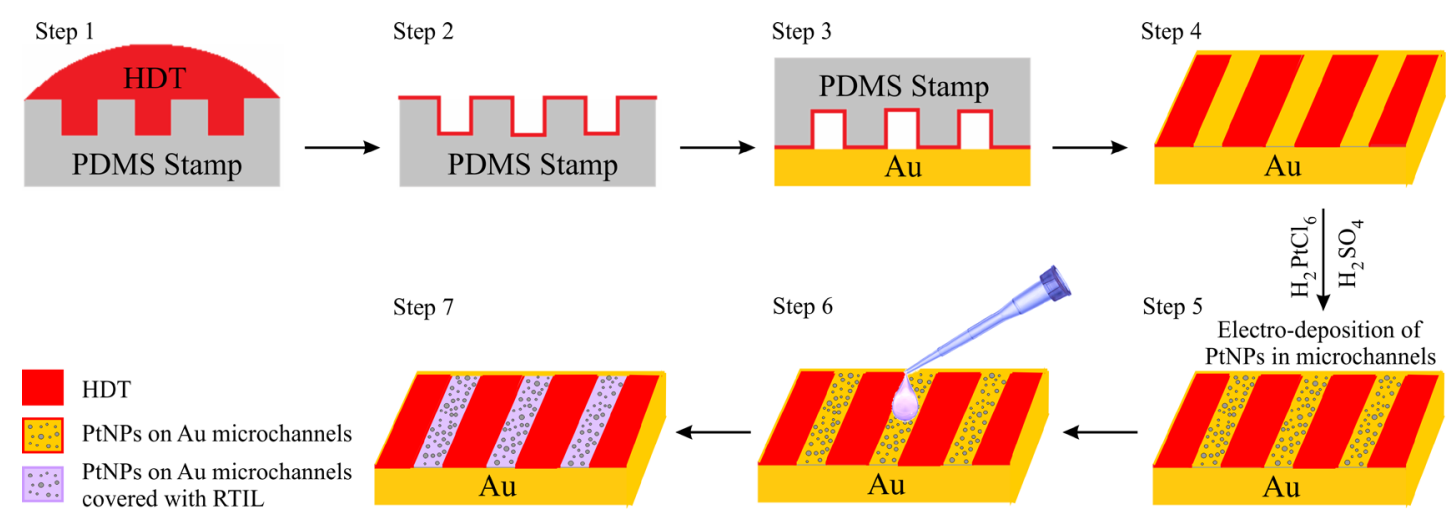

Figure 1: Schematic illustration of the protocol for the creation of Au microchannels with HDT and the electrochemical deposition of PtNPs into the Au microchannels.

In step 5, the Au microchannels were electrochemically modified with platinum nanoparticles (PtNPs), since hydrogen has very sluggish kinetics on gold surfaces [30]. For this, the HDT modified electrode was employed in a conventional three electrode arrangement, with a $\mathrm{Ag} / \mathrm{AgCl}$ reference electrode $(0.1 \mathrm{M} \mathrm{KCl}, \mathrm{BASi}$, Indiana, USA) and a Pt wire counter electrode (diameter $0.5 \mathrm{~mm}$, Goodfellow, Cambridge Ltd., UK), suspended into a home-made glass cell containing $3 \mathrm{~mL}$ of a deaerated solution of $5 \mathrm{mM} \mathrm{H}_{2} \mathrm{PtCl}_{6}$ in $0.5 \mathrm{M} \mathrm{H}_{2} \mathrm{SO}_{4}(\mathrm{aq})$. Electrochemical deposition of PtNPs was achieved by holding at the open circuit potential (ca. $0.68 \mathrm{~V}$ ), then stepping the potential to $-0.2 \mathrm{~V}$ and holding for 
10 seconds. After deposition, the electrode was washed with ultrapure water and dried under nitrogen. To fill the PtNPs Au microchannels with RTIL (step 7), a tiny droplet of RTIL was drop-casted and then spread with the help of micropipette tip. Excess RTIL was removed using lint-free tissue or by back suction with a micropipette. The total volume used in the microchannels was estimated to be $\sim 10 \mathrm{~nL}$. To connect the Pt wire counter and Ag-wire quasireference electrodes, a tiny droplet of RTIL was drop-cast close to one end of the microchannels on the insulating plastic body of the working electrode. The Ag and Pt wires were dipped into the droplet at an angle of $\sim 120^{\circ}$. A schematic of the experimental set-up with the microchannels [44] vs a regular macrodisk electrode also employed in this work is shown in Figure 2. The PtNP microchannel electrodes were found to be quite stable and can be reactivated and reused after six months if covered with a cap and stored under vacuum in a temperature-controlled lab.
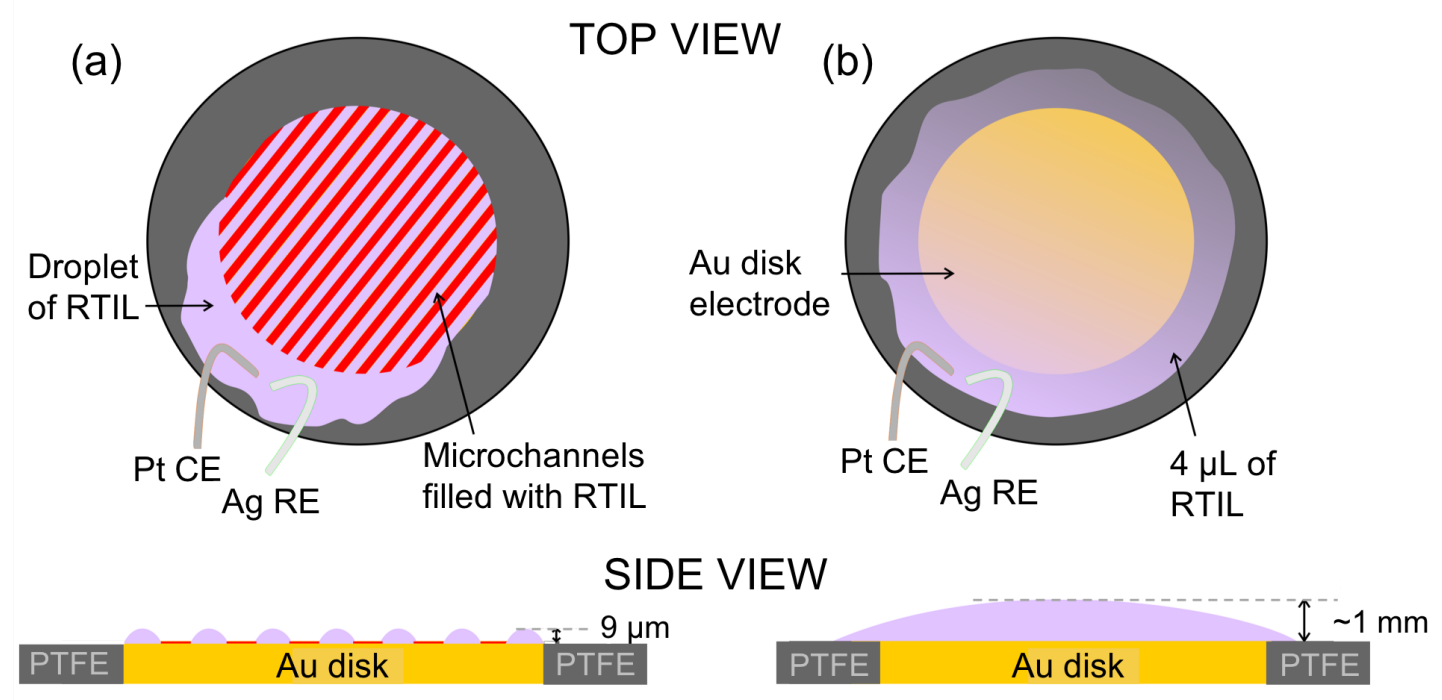

Figure 2: Illustration of the experimental set-up (not to scale) for (a) a Au microchannel electrode and (b) a traditional Au macrodisk electrode, encased in a PTFE cylinder. Platinum and silver wires (counter and reference electrode, respectively) were dipped into the RTIL at an angle of $120^{\circ}$ to the side of the Au electrode disk.

\subsection{Electrochemical Experiments}

All experiments were performed using a PGSTAT101 Autolab potentiostat (Eco, Chemie, Netherlands) interfaced to a PC with Nova 1.11 software, at laboratory room temperature $(294 \pm 1 \mathrm{~K})$ in a fume cupboard, inside an aluminium Faraday cage to reduce electrical interference. Gold $(\mathrm{Au})$ and platinum $(\mathrm{Pt})$ conventional macrodisk electrodes (diameter $1.6 \mu \mathrm{m}$ ) from BASi (Indiana, USA) were employed as gas sensing surfaces. Prior to experiments, the surface of the $\mathrm{Au}$ and Pt electrodes were polished on soft polishing pads (Buehler Illinois) with decreasing size of alumina powder $(3 \mu \mathrm{m}, 1 \mu \mathrm{m}$ and $0.05 \mu \mathrm{m}$, Kemet, NSW, Australia). After polishing, the electrodes were cleaned by ultrasonication first in ethanol, then in ultrapure water for 5 minutes each, and finally washed with ultrapure water and dried under a nitrogen stream. For gas sensing experiments, PtNP-modified Au microchannels were employed, along with unmodified $\mathrm{Au}$ and $\mathrm{Pt}$ macrodisk electrodes for comparison. A fourth surface was also employed, consisting of a Au macrodisk surface covered with PtNPs, where the nanoparticles were electrodeposited using the same method and time as above.

For gas sensing experiments, all working electrodes were connected with a Pt wire counter electrode and a silver (Ag) wire quasi-reference electrode, shown in Figure 2. $4 \mu \mathrm{L}$ of RTIL was drop-cast on all macrodisk electrodes (but not on 
the microchannels). The electrochemical cell was placed into a modified rubber bung and then housed in a specially designed glass T-cell [45], closed at the top with a glass stopper. The cell had two openings: an inlet from where the analyte gas (hydrogen, nitrogen fill) enters and passes over the electrodes, and an outlet to allow the gas to be released into the fume cupboard. Prior to the introduction of hydrogen gas, the cell was purged with nitrogen to remove any dissolved gases present in the RTIL. When the baseline was stable (after ca. 20 minutes), hydrogen gas was introduced into the cell and continuously flowed over the electrode.

Prior to recording cyclic voltammetry, the potential was held at $+2.0 \mathrm{~V}$ for 60 seconds for pretreatment of the electrode surface [30]. For long-term chronoamperometry experiments, the potential was stepped from a position of zero current and then held at a suitable overpotential under nitrogen until a stable baseline was obtained. Hydrogen gas was then introduced into the cell at different concentrations in nitrogen (10-100 vol- $\%$ or $1-10$ vol- $\%$ vol. $\left.\mathrm{H}_{2}\right)$ until a stable, steady-state response was obtained. A nitrogen flushing step was employed between each concentration change to observe the stability of the baseline.

\subsection{Gas Mixing System}

A high purity hydrogen gas cylinder (99.99\%) was used and diluted with nitrogen gas using a gas mixing system as reported previously [45]. This consists of two digital flow meters $(0-1.0 \mathrm{~L} / \mathrm{min}$, John Morris Scientific, NSW, Australia), one connected with the hydrogen gas cylinder and other with the nitrogen cylinder through PTFE tubing via a Swagelok T-joint (Swagelok, Kardinya, WA, Australia). The mixture of both gases $\left(\mathrm{H}_{2} / \mathrm{N}_{2}\right)$ was then passed through an additional gas-mixing segment to increase turbulence [45], ensuring adequate mixing of both gases. The relative flow rates were used to calculate the different concentrations of hydrogen gas introduced into the cell.

\subsection{Electrode Imaging}

A light microscope (Nikon Optiphot-2) was used to take optical images of unmodified and RTIL filled Au microchannels. Scanning electron microscopy (SEM) was performed on the bare Au microchannels and PtNP modified Au microchannel electrodes. SEM Images were obtained using MIRA3 (MIRA VP-FESEM), with an accelerating voltage of $5.0 \mathrm{kV}$. The size and density of the deposited nanoparticles were measured using Image $\mathrm{J}$ software. Atomic force microscopy (AFM) was performed using a WITech alpha 300SAR, to investigate the morphology of the PtNPs, the depth of the Au microchannels, and the thickness of the blocking HDT layer. Energy Dispersive X-Ray Spectroscopy (EDS) was performed to confirm that no Pt was deposited on the HDT layer. 


\section{RESULTS AND DISCUSSION}

\subsection{Characterization of Bare and PtNP Modified Gold Microchannels}

In this study, platinum nanoparticle (PtNP) modified gold microchannels are employed as a new type of electrode for the electrochemical detection of hydrogen. Figure 3a shows a SEM image of the electrode, with bare Au microchannels (light grey) and printed HDT channels (dark grey). The HDT layer has a uniform thickness of $52 \pm 1 \mathrm{~nm}$, measured by atomic force microscopy on several electrodes prepared. Figure $3 \mathrm{~b}$ shows a close-up image of one Au microchannel modified with PtNPs, next to a HDT modified channel. The nanoparticles were deposited from a solution of $5 \mathrm{mM}$ $\mathrm{H}_{2} \mathrm{PtCl}_{6}$ in $0.5 \mathrm{M} \mathrm{H}_{2} \mathrm{SO}_{4}$, with the HDT patterned electrode dipped into the bulk solution. It can be seen that there is no deposition of PtNPs in the HDT channels, confirming that these parts of the surface are electrochemically inactive (also confirmed using EDS). The HDT channels thus act as an insulating layer, likely due to the long chain of carbon atoms attached to the thiol group, leaving only $\sim 50 \%$ of the geometric area of the electrode electrochemically active. The size and density of PtNPs was found to be $54 \pm 20 \mathrm{~nm}$ and $254 \pm 0.2 \mathrm{NPs} / \mu \mathrm{m}^{2}$, respectively, measured using image $\mathrm{J}$ software. The size and density can be adjusted by modifying the parameters (deposition time, Pt complex concentration, potential etc.) if necessary, but these parameters were fixed in our experiments. Under these deposition conditions, the nanoparticles are relatively dense and closely packed, and are not expected to behave as individual microelectrodes. The total electroactive surface area (ESA) of the platinum nanoparticles (PtNPs on Au microchannels) was calculated from the charge of the hydrogen desorption peaks using standard procedures [46, 47], with the electrode dipped into the bulk solution ( $0.5 \mathrm{M} \mathrm{H}_{2} \mathrm{SO}_{4}(\mathrm{aq})$ ), and was found to be $3.03 \pm 0.2 \mathrm{~mm}^{2}$. For comparison, this is ca. $74 \%$ of the ESA of a PtNP modified gold electrode $\left(4.11 \pm 0.3 \mathrm{~mm}^{2}\right.$, modified using the same procedure, but without the HDT stamp), and ca. $82 \%$ of the bare Pt electrode $\left(3.71 \pm 0.2 \mathrm{~mm}^{2}\right)$.

Optical images of the Au microchannels are shown in Figure 3c, and the same microchannels filled with RTIL are shown in Figure 3d. The channels have a uniform width of $52 \mu \mathrm{m}$ (HDT pattern), separated by a bare Au channel of width $48 \mu \mathrm{m}$. When a drop of RTIL is placed on the electrode surface, the RTIL spontaneously fills the Au microchannels, but does not fill the HDT covered channels (Figure 3b). This is due to the hydrophobic nature of both HDT and the RTIL, so the RTIL only fills the uncovered hydrophilic gold substrate, and is attributed to the different strengths of intermolecular forces between two surfaces, which generally follow a trend of hydrophobic/hydrophobic $<$ hydrophilic/ hydrophobic < hydrophilic/hydrophilic [48]. The amount of RTIL was not optimised, since the spontaneous filling of the channels appeared to be highly reproducible each time. The thickness of the RTIL in the filled $\mathrm{Au}$ microchannels is estimated to be $\sim 9 \mu \mathrm{m}$ using atomic force microscopy (AFM) coupled with WITech alpha $300 \mathrm{SAR}$, suggesting that a volume of only $\sim 10 \mathrm{~nL}$ is required to fill the microchannels (noting the additional small volume required to connect the $\mathrm{CE}$ and RE as shown in Figure 2a) and is consistent with a previous study [49]. Such a thin film of RTIL is highly favorable to enhance the response time for gas sensing experiments, as will be exploited in this work. The micron-sized thickness is significantly smaller than that required for the conventional macrodisk electrodes, where a minimum of $\sim 4 \mu \mathrm{L}$ of RTIL ( $1 \mathrm{~mm}$ thickness) is usually required to properly connect the electrodes (see Figure 2b). 

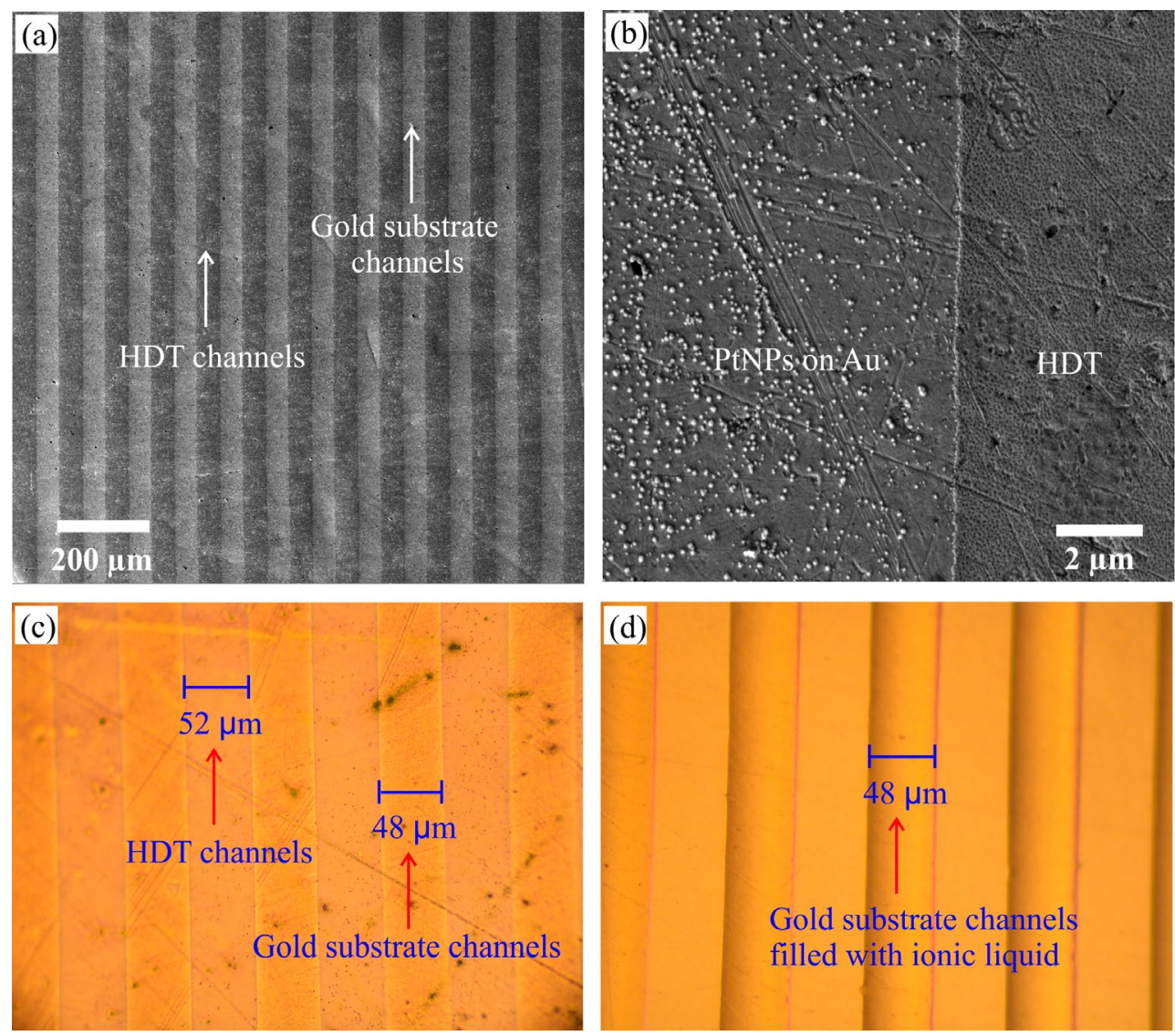

Figure 3: Scanning electron microscopy (SEM) images of (a) bare Au microchannels, (b) close-up of electrodeposited PtNP modified Au microchannels. Optical images of: (c) Au microchannels made by a HDT stamp on a gold macrodisk electrode, and (d) the same Au microchannels filled with ionic liquid (width of Au microchannels $=48 \mu \mathrm{m}$, width of HDT microchannels $=52$ $\mu \mathrm{m})$.

\subsection{Hydrogen Oxidation on Bare and Microchannel Electrodes}

To demonstrate the benefits of the microchannels for hydrogen oxidation, four surfaces were employed: (i) bare platinum, (ii) bare gold, (iii) PtNP modified gold, and (iv) PtNP modified Au microchannels. The RTIL [C $\mathrm{C}_{2}$ im] $\left[\mathrm{NTf}_{2}\right]$ was chosen as the electrolyte due to its relatively low viscosity, known chemically reversible voltammetry and clear peak shaped response for 100 vol-\% hydrogen [30, 31]. Figure 4 shows overlaid cyclic voltammograms (CVs) for the oxidation of 100 vol- $\%$ hydrogen at a scan rate of $100 \mathrm{mVs}^{-1}$. No clear oxidation peaks were observed on the bare gold electrode (red CV), since hydrogen is reported to have sluggish kinetics on gold surfaces, resulting in no oxidation peaks occuring in the available potential window [30, 31]. On both the PtNP modified gold electrode (black CV), and bare Pt electrode (blue CV), a transient (peak) shaped voltammetric response was obtained, corresponding to the reversible oxidation of hydrogen, given in equation 1 [30].

$$
\mathrm{H}_{2}(\mathrm{~g})+2 \mathrm{~A}^{-} \rightleftharpoons 2 \mathrm{HA}+2 \mathrm{e}^{-}
$$

where $\mathrm{A}^{-}$is the RTIL anion $\left(\left[\mathrm{NTf}_{2}\right]^{-}\right)$. The reverse scan corresponds to the reduction of the electrogenerated solvated proton, HA [30, 31].

A slightly larger peak current on the PtNP modified Au electrode is probably due to the increased electroactive surface area compared to the bare Pt electrode. The mid-point potential for the $\mathrm{H}_{2} / \mathrm{H}^{+}$redox couple is ca $-0.1 \mathrm{~V}$ vs the $\mathrm{Ag}$ quasi- 
reference electrode, and a peak-to-peak separation $\left(\Delta E_{\mathrm{p}}\right)$ of ca. $115 \mathrm{mV}$ was measured for both surfaces, suggesting that the oxidation of hydrogen in $\left[\mathrm{C}_{2} \mathrm{mim}\right]\left[\mathrm{NTf}_{2}\right]$ is an electrochemically quasi-reversible process, consistent with previous reports [30,39]. It is also noted that at potentials more positive than $+0.3 \mathrm{~V}$, a small shoulder appeared in the limiting current region on the bare Pt electrode (results not shown), that could be due to the oxidation of an oxide layer (e.g. PtO) or impurities present on the surface of the electrode [30]. This is not evident on the PtNP modified Au electrode, where fresher Pt electrodeposits are employed. In aqueous solvents the $\mathrm{H}_{2} / \mathrm{H}^{+}$redox reaction is known to affect the local $\mathrm{pH}$ at the electrode, which can shift the observed formal potential [50]. However, $\mathrm{pH}$ effects are much more complicated in RTILs [51] so it is difficult to comment on how the formal potential might be affected in our experiments. Additionally, the reference electrode employed is a silver wire which itself is likely to be susceptible to large potential shifts in the presence of hydrogen [52]. Therefore, the interpretation of CVs are discussed from a purely analytical nature, in terms of peak shapes and currents.

In contrast with the peak-shaped CVs, the voltammetric response for hydrogen oxidation on the PtNP modified gold microchannel electrode (green CV) has a steady-state shaped oxidation response. On the reverse sweep, the reduction is peak shaped and transient in nature, likely due to the different diffusion coefficient of the electrogenerated proton compared to hydrogen [30,53-56], a phenomenon that was also observed previously for the oxygen/superoxide redox couple in RTILs [54]. The steady-state hydrogen oxidation voltammetry becomes more peak shaped at higher scan rates (not shown here), with a peak-to-peak separation of $\sim 222 \mathrm{mV}$ at $1 \mathrm{Vs}^{-1}$. In addition to having a very different $\mathrm{CV}$ shape, the voltammetric current obtained on the PtNPs Au microchannels is ca. three times smaller than the other surfaces, much greater than the difference in the electroactive surface areas. We believe this is due to the geometry of the Au microchannels and the small electrolyte thickness $(9 \mu \mathrm{m})$ employed for the gas sensing experiments. The diffusion layer thickness is estimated to be $\sim 57 \mu \mathrm{m}$, using $(D t)^{0.5}$, where $D$ is the diffusion coefficient of hydrogen $\left(5.5 \times 10^{-10} \mathrm{~m}^{2} \mathrm{~s}^{-1}\right)[31]$ and $t$ is the timescale of a typical voltammetric experiment (ca. 6 seconds). In this case, the behaviour is characteristic of a thin layer cell $[57,58]$, where the voltammetric response is expected to get smaller as the electrolyte layer gets thinner [58], resulting in the reduced current response observed in the green line in Figure 4.

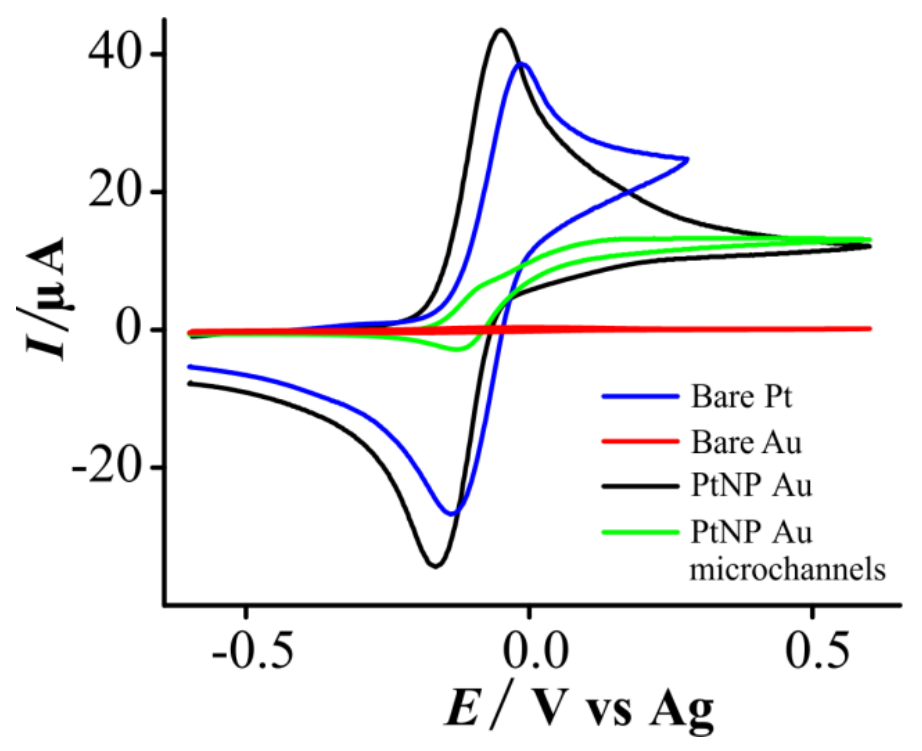

Figure 4: Electrochemical oxidation of 100 vol- $\% \mathrm{H}_{2}$ on (blue) bare Pt electrode, (red) bare gold electrode, (black) PtNP modified gold electrode, (green) PtNP modified Au microchannels in $\left[\mathrm{C}_{2} \mathrm{mim}\right]\left[\mathrm{NTf}_{2}\right]$ at a scan rate of $100 \mathrm{mVs}^{-1}$.

3.3 Analytical Response for Hydrogen Oxidation 
To test the different electrodes for their ability to detect hydrogen, and to calculate response times, hydrogen oxidation was studied at different concentrations from $10-100$ vol- $\% \mathrm{H}_{2}$ in $\left[\mathrm{C}_{2} \mathrm{mim}\right]\left[\mathrm{NTf}_{2}\right]$. Two electrochemical techniques were employed, at both short and long timescales: cyclic voltammetry (CV) and long-term chronoamperometry (LTCA).

\subsubsection{Cyclic Voltammetry}

Figure 5 shows cyclic voltammetry (CV) for the oxidation of $10-100$ vol- $\%$ of hydrogen in $\left[\mathrm{C}_{2} \mathrm{mim}\right]\left[\mathrm{NTf}_{2}\right]$ on (a) a PtNP modified Au microchannel electrode, (b) a bare Pt electrode, and (c) a PtNP modified gold electrode at a scan rate of $100 \mathrm{mVs}^{-1}$. The red dashed line shows the blank response in the absence of hydrogen. The insets show the corresponding calibration plots of oxidation peak currents (baseline corrected) vs gas phase hydrogen concentration. On the PtNP modified Au microchannel electrode, a steady state response was obtained at all concentrations for the oxidation process, while the reverse process was peak shaped. The steady state oxidation currents were measured from a fixed potential of $+0.4 \mathrm{~V}$ and were plotted against the respective concentrations (see inset to Figure $4 \mathrm{a}$ ), with excellent linearity $\left(R^{2}=0.999\right)$ obtained. The current response was highly reproducible when repeated experiments $(n=3)$ were performed on the same electrode, with error bars (one standard deviation) that were less than $4 \%$ on all surfaces. The calibration graph is significantly more linear than on the bare Pt electrode (Figure $5 \mathrm{~b}, R^{2}=0.979$ ), which shows some curvature at higher concentrations. Since the $\mathrm{H}_{2}$ oxidation process is reported to be more complicated than a simple diffusion-controlled process on platinum (e.g. due to the presence of surface oxides) $[30,38,39]$, some deviation from linearity is not surprising. The response on the PtNP modified gold macrodisk electrode is very similar $\left(R^{2}>0.999\right)$ to the bare Pt electrode. The better response on the PtNP modified electrodes may be due to the fresher Pt deposits, and less surface oxide formation compared to the bare Pt electrode. 

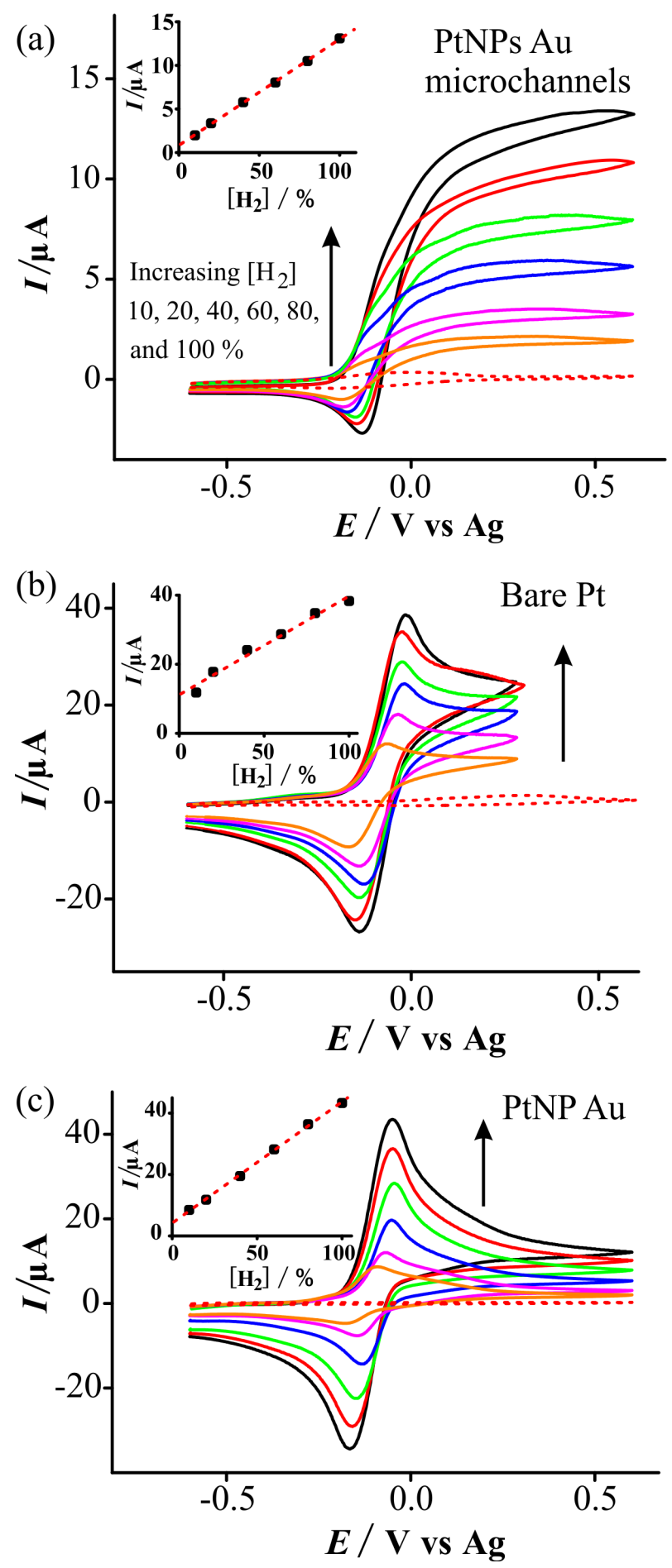

Figure 5: Cyclic voltammetry for the electrochemical oxidation of $10-100$ vol- $\% \mathrm{H}_{2}$ on a (a) PtNP modified Au microchannel electrode, (b) bare Pt electrode, and (c) PtNP modified gold electrode in $\left[\mathrm{C}_{2} \mathrm{mim}\right]\left[\mathrm{NTf}_{2}\right]$ at a scan rate of $100 \mathrm{mVs}^{-1}$. Red dashed line is blank voltammogram in the absence of $\mathrm{H}_{2}$. Insets show the calibration plots of peak current (baseline corrected) vs concentration, along with the line of best fit. Error bars for one standard deviation $(n=3)$ are very small (between $2-4 \%)$ and hence are not easily visible on the calibration plots.

Table 1 shows the analytical parameters resulting from the calibration plots for $10-100$ vol- $\%$ hydrogen oxidation. The sensitivity values were calculated from the gradient of the line of best fit, and limits of detection (LODs) were calculated using three times standard deviation of the line. The PtNP modified Au microchannel electrode had the lowest sensitivity using CV, consistent with its smaller electroactive surface area and lower current observed in Figure 4. The sensitivities were slightly higher on the PtNP modified gold electrode compared to the bare platinum, as expected due to its larger electroactive surface area. The LODs on the PtNP modified Au microchannel electrodes 
were ca. 7 times smaller (2.5\%) than the bare Pt electrodes (17\%), and well below the lower explosive limit (LEL) for hydrogen (4 vol-\%).

Table 1: Analytical parameters calculated for hydrogen oxidation in $\left[\mathrm{C}_{2} \operatorname{mim}\right]\left[\mathrm{NTf}_{2}\right]$ on PtNP modified Au microchannels, along with bare Pt and PtNP modified Au macrodisk electrodes using cyclic voltammetry (CV) and long-term chronoamperometry (LTCA).

\begin{tabular}{|c|c|c|c|c|c|c|c|}
\hline \multirow[b]{2}{*}{ Electrode } & \multicolumn{3}{|c|}{$\mathrm{CV}$} & \multicolumn{2}{|c|}{ LTCA } & \multirow[b]{2}{*}{$\begin{array}{c}\text { Response time } \\
\left(t_{90}\right) / \mathrm{s}\end{array}$} & \multirow[b]{2}{*}{$\begin{array}{c}\text { Recovery time } \\
\left(t_{90, \mathrm{r}}\right) / \mathrm{s}\end{array}$} \\
\hline & $\begin{array}{l}\text { Concentration } \\
\text { range / vol- } \%\end{array}$ & $\begin{array}{c}\text { Sensitivity } \\
/ \mathrm{A}^{-1}{ }^{-1}\end{array}$ & $\begin{array}{l}\text { LOD } \\
/ \text { vol-\% }\end{array}$ & $\begin{array}{c}\text { Sensitivity } \\
/ \mathrm{A} \% \%^{-1}\end{array}$ & $\begin{array}{l}\text { LOD } \\
/ \text { vol-\% }\end{array}$ & & \\
\hline $\begin{array}{l}\text { PtNP Au } \\
\text { Microchannels }\end{array}$ & $10-100$ & $1.2 \times 10^{-7}$ & 2.5 & $9.6 \times 10^{-8}$ & 3.4 & $2( \pm 0.4)$ & $184( \pm 15)$ \\
\hline Bare Pt & $10-100$ & $2.9 \times 10^{-7}$ & 17 & $5.2 \times 10^{-8}$ & 24 & $46( \pm 5)$ & $203( \pm 29)$ \\
\hline PtNP Au & $10-100$ & $4.0 \times 10^{-7}$ & 3.9 & $8.2 \times 10^{-8}$ & 3.6 & $39( \pm 4)$ & $206( \pm 16)$ \\
\hline $\begin{array}{l}\text { PtNP Au } \\
\text { Microchannels }\end{array}$ & $1-10$ & $2.1 \times 10^{-7}$ & 0.4 & $1.5 \times 10^{-7}$ & 0.1 & $2( \pm 0.2)$ & $191( \pm 13)$ \\
\hline
\end{tabular}

Error bars for response and recovery times represent one standard deviation of response times for all six concentrations of $\mathrm{H}_{2}$.

\subsubsection{Long-Term Chronoamperometry}

In order to test the ability of the modified surfaces for "real-time" hydrogen gas sensing and to measure the response time ( $\left.t_{90}\right)$, long-term chronoamperometry (LTCA) was performed for 10-100 vol- $\%$ hydrogen in $\left[\mathrm{C}_{2} \mathrm{mim}\right]\left[\mathrm{NTf}_{2}\right]$ on the three electrodes. For this, initially the electrochemical cell was purged with $99.99 \%$ nitrogen for ca. 20 minutes and then the potential was stepped from $-0.45 \mathrm{~V}$ to a suitable overpotential (e.g. $+0.6 \mathrm{~V}$ for PtNP modified Au microchannels) and held for an extended period until a stable baseline was obtained. Hydrogen gas was then introduced into the cell at different concentrations (10-100 vol-\%) for a sufficient time (ca. 100-150 seconds) to observe a plateau current. During each different concentration change, nitrogen 'flushing' was performed for ca. 200 seconds to observe a return to the baseline.

Figure 6a shows the long-term chronoamperometric current-time (I-t) response for 100-10 vol-\% hydrogen in $\left[\mathrm{C}_{2} \mathrm{mim}\right]\left[\mathrm{NTf}_{2}\right]$ on the PtNP modified Au microchannel electrode, along with the corresponding calibration plot of current vs concentration. Initially, the current is close to zero in the absence of hydrogen. When hydrogen gas is introduced into the cell, an extremely quick instantaneous response is observed, and the current reaches a maximum within a few seconds. The ultra-fast response is probably due to the thin layer of the RTIL (high surface to volume ratio), and the fast partitioning of $\mathrm{H}_{2}$ gas; using a constant biasing technique, the diffusion layer is already extended to the edge of the gas/liquid interface and instantly responds when the gas concentration is changed. There is a slight drop in current after the maximum at the higher concentrations (which becomes less pronounced at the lower concentrations), which could be due to the stabilization of concentration of $\mathrm{H}_{2}$ as the experiment progresses. However, on the PtNP modified Au and bare Pt electrodes (see Figures $6 \mathrm{~b}$ and $6 \mathrm{c}$ ), the current does not plateau, but continues to increase over time, probably due to the slower partitioning of $\mathrm{H}_{2}$ into the larger droplet of RTIL. Only at the lowest concentrations were more stable plateau currents obtained. The maximum currents were plotted vs concentration (see insets to Figure 6). The sensitivities and LODs were calculated from the line of best fit and are reported in Table 1. The 
highest sensitivity ( $96 \mathrm{nA} / \%$ ) was obtained on the PtNP modified Au microchannels. A slightly smaller sensitivity (82 $\mathrm{nA} / \%$ ) was obtained on the PtNP modified Au macrodisk, and comparatively, the smallest sensitivity (52 nA/\%) was obtained on the bare Pt macrodisk electrode. The sensitivities appear to be an order of magnitude smaller than for CV, however the highest sensitivity is now observed on the PtNP modified Au microchannels. This suggests that the diffusion layer thickness has extended significantly on the other surfaces also and is now larger than the thickness of the RTIL droplet (ca. $1 \mathrm{~mm}$ ). Figure 6d shows a comparison of the LTCA response for one chosen concentration (60 vol-\% hydrogen) in $\left[\mathrm{C}_{2} \mathrm{mim}\right]\left[\mathrm{NTf}_{2}\right]$ on the three surfaces, showing a higher current on the PtNP modified $\mathrm{Au}$ microchannel electrode. Table 1 shows the analytical parameters extracted from the LTCA calibration plots, along with the response times.

The response time $\left(t_{90}\right)$ is an important parameter to test the speed of a sensor to respond to a particular gaseous analyte. In this work, it is defined as the time taken to reach $90 \%$ of the maximum current from the baseline [59], and the calculated values have been included in Table 1. On the PtNP modified Au microchannel electrode, a very fast response time of 2 seconds was obtained, which is $\sim 20$ times faster than macrodisk electrode ( $39 \pm 7$ seconds) where a larger droplet of RTIL has been employed. Importantly, this fast response time was very consistent for different concentrations between 10-100 vol-\% hydrogen and on several $(n=3)$ repeat experiments. The excellent performance (fast response time, and high sensitivity) of the PtNP Au microchannel electrode compared to the macrodisk electrodes (PtNPs Au, and bare $\mathrm{Pt}$ ) is attributed to the presence of the microchannels with only a very thin layer of ionic liquid $(9 \pm 0.5 \mu \mathrm{m})$. The small thickness of the microchannels allows fast saturation of the gas in the RTIL, and only a small distance for the gas to reach the electrode surface. It is important to note here, the fast response time for hydrogen relative to other gases (e.g. oxygen: $50 \mathrm{~s}$ [43], ammonia and hydrogen chloride: 15-30 s [44]) in RTILs on the microchannels is probably due to the small size of the hydrogen molecules - which can facilitate their fast partitioning into the liquid phase - as well as the fast kinetics of hydrogen oxidation at the PtNP catalysts. Recovery times $\left(t_{90, \mathrm{r}}\right)$, defined as the time required for a sensor to return to $90 \%$ of the original baseline signal upon removal the target gas, are also shown in Table 1. For amperometric gas sensors, recovery times are typically much longer than the response times, and were similar between the three surfaces ( $\sim 3$ to 3.5 minutes). 

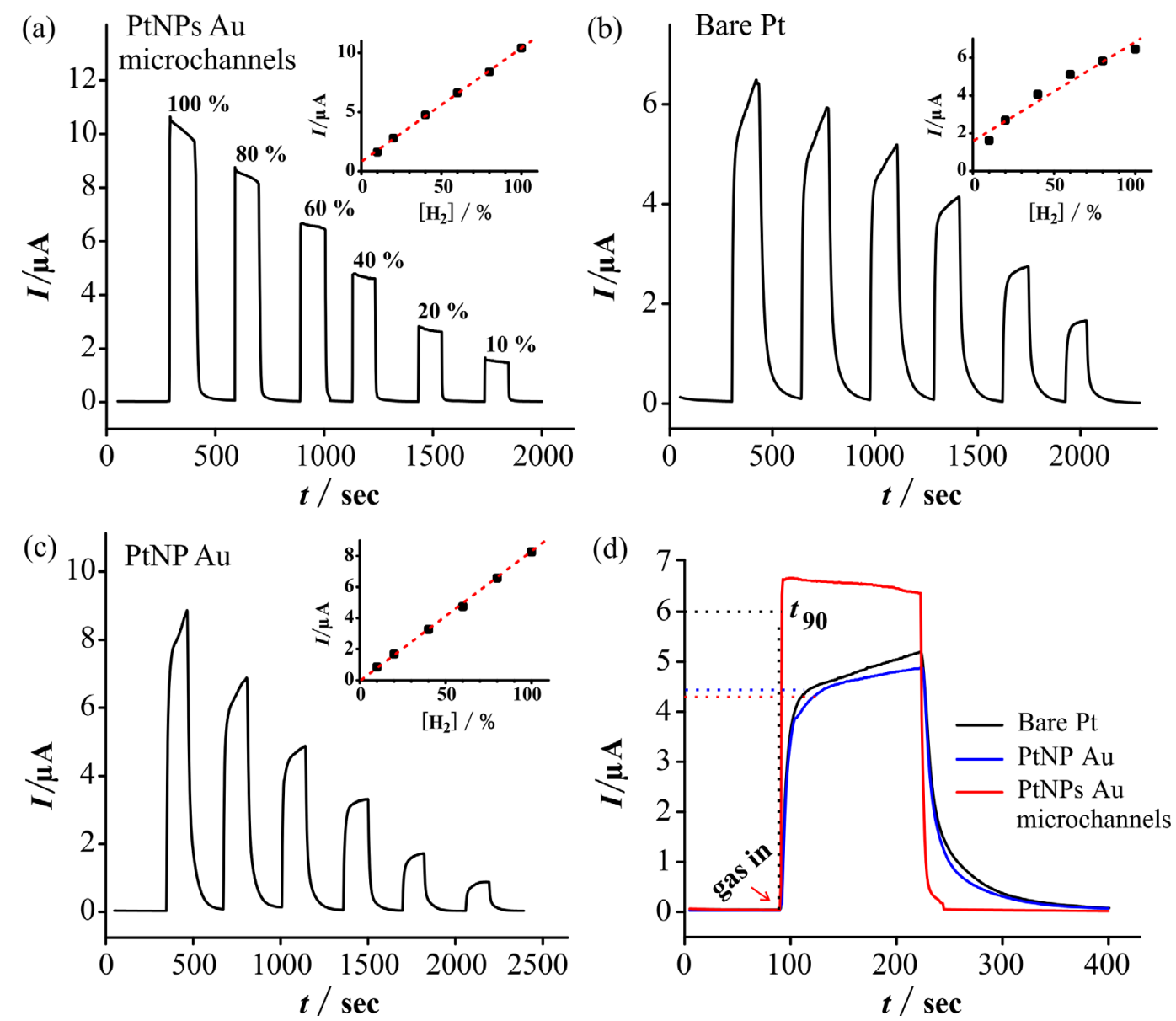

Figure 6. (a) Long-term chronoamperometry (LTCA) for (a) 100-10 vol- $\% \mathrm{H}_{2}$ on (a) PtNP modified Au microchannels, (b) bare Pt electrode, (c) PtNP modified gold electrode. Insets show the corresponding calibration plot of current (baseline corrected) vs concentration, along with the line of best fit. Error bars for one standard deviation $(n=3)$ are very small (between $2-4 \%)$ and hence are not easily visible on the calibration plots. (d) Comparison of current response for $60 \mathrm{vol}-\% \mathrm{H}_{2}$ on the three surfaces.

\subsubsection{Lower Concentration Study}

A lower concentration range of hydrogen was studied to determine the ability of the PtNP modified Au microchannel electrode to detect relevant concentrations closer to the lower explosive limit. Figure 7 shows (a) cyclic voltammetry and (b) long-term chronoamperometry for the oxidation of 1, 2, 4, 6, 8 and 10 vol- $\% \mathrm{H}_{2}$, with the response in the absence of hydrogen shown as a dotted line. At lower $\mathrm{H}_{2}$ concentrations, the small impurity in the blank RTIL is more obvious (see dotted line in (a)), but can be background-subtracted to produce a good linear calibration graph $\left(R^{2}=\right.$ 0.998). LTCA (Figure 7b) shows current responses that are well distinguished from the baseline at these low-percentage concentrations. The sensitivity (gradient of calibration line) for the $1-10$ vol- $\%$ range is slightly higher than for the 10 100 vol-\% range (see Table 1), which from our experience is an artefact of the higher total flow rate required to produce the lower concentrations from the same gas cylinder. The LOD is 0.1 vol- $\% \mathrm{H}_{2}$, well below the lower explosive limit, and we note this could likely be even lowered further if a lower concentration range is studied.

In order to test the reproducibility of the PtNP modified Au microchannel electrode for long-term monitoring of hydrogen gas at concentrations near the LEL, long-term chronoamperometry (LTCA) was performed at a constant concentration of 4 vol- $\% \mathrm{H}_{2}$ in $\left[\mathrm{C}_{2} \mathrm{mim}\right]\left[\mathrm{NTf}_{2}\right]$, with a nitrogen 'flushing' step in between. Figure $7 \mathrm{c}$ shows the LTCA response for multiple additions of 4 vol-\% hydrogen in $\left[\mathrm{C}_{2} \mathrm{mim}\right]\left[\mathrm{NTf}_{2}\right]$ on freshly prepared different PtNPs modified microchannels electrodes $(n=3)$. The corresponding plots for maximum current and the response times for different additions $(n=5)$ of hydrogen are shown in Figure $7 \mathrm{~d}$. A stable and highly reproducible current response was obtained 
for 4 vol-\% hydrogen with a steady baseline, suggesting that this is a highly favorable electrode design to reproducibly detect hydrogen gas. Additionally, the reproducibility was excellent on freshly prepared nanoparticle-covered microchannels (less than $6 \%$ current variation for three separate preparations) confirming that the nanoparticle deposition method in the channels was highly consistent.
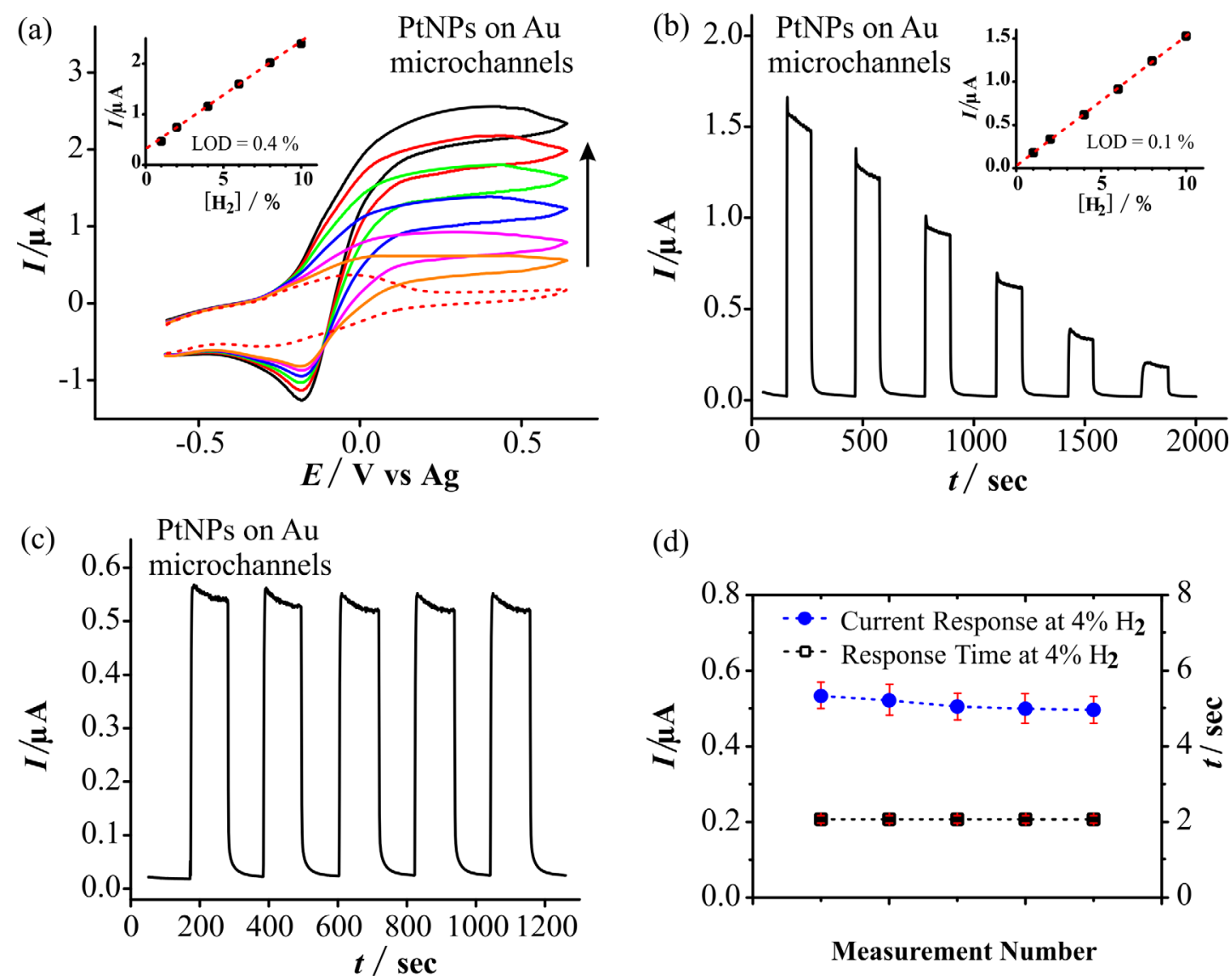

Measurement Number

Figure 7. (a) Cyclic voltammetry, and (b) long-term chronoamperometry (LTCA), response on a PtNP modified Au microchannel electrode for $1-10$ vol- $\% \mathrm{H}_{2}$. Insets show corresponding calibration graphs. (c) Reproducibility experiment using LTCA for $4 \%$ $\mathrm{H}_{2}$, and (d) current response and response time at $4 \% \mathrm{H}_{2}$ vs the number of measurements on PtNP modified Au microchannels in $\left[\mathrm{C}_{2} \mathrm{mim}\right]\left[\mathrm{NTf}_{2}\right]$. For all LTCA experiments, the potential was stepped from $-0.45 \mathrm{~V}$ to $+0.6 \mathrm{~V}$. The error bars shown in (d) represent one standard deviation of measurements on three separate freshly-prepared PtNP microchannel electrodes.

\section{CONCLUSIONS}

The detection of hydrogen on PtNP modified Au microchannel electrodes in $\left[\mathrm{C}_{2} \mathrm{mim}\right]\left[\mathrm{NTf}_{2}\right]$ has been demonstrated for the first time. Voltammetric wave shapes indicate that thin-layer diffusion occurs in the channels, compared to classical diffusional behavior on the macrodisk electrodes. The CV currents for 10-100 vol-\% hydrogen showed excellent linearity on the PtNP modified Au microchannel electrode, resulting in the lowest LOD (2.5 vol-\%) out of all the electrodes, despite having the lowest sensitivity. The response time ( $\left.t_{90}\right)$ and "real time" detection of hydrogen was measured using LTCA. A very fast response time of 2 seconds on the modified microchannels, ca. 20 times faster than that observed on the macrodisk electrodes. At the lower concentration range, an LOD of 0.1 vol- $\% \mathrm{H}_{2}$ was observed, which is much smaller than the lower explosive limit, suggesting the possibility to use this electrode design to quickly quantify hydrogen in the case of a spontaneous gas leak, before it poses a risk of an explosion. Future work may include studying $\mathrm{H}_{2}$ oxidation in a background of air, and also in the presence of other interfering gases to show the usefulness of such a sensor in real gaseous environments. The use of electrocatalysts such as platinum nanoparticles 
effectively extend the application of this electrode design to detect and quantify an even wider range of target gas analytes.

\section{ACKNOWLEDGEMENTS}

DSS thanks the Australian Research Council (ARC) for funding via a Discovery Early Career Award (DECRA, DE120101456). GH thanks Curtin University, the Department of Chemistry and the Curtin Institute for Functional Molecules and Interfaces (CIFMI) for a PhD scholarship. CZ thanks ARC for the funding of a Discovery Grant (DP150101861). The authors acknowledge the use of equipment of the Curtin University Electron Microscope Facility, which is partially funded by the University, State and Commonwealth Governments of Australia (thanks to Ms Elaine Miller for technical assistance), and the use of the instruments of the Scanning Probe Microscopy facility at Curtin University, funded by ARC LIEF grant number LE130100121. 


\section{REFERENCES}

[1] B.J. Dixon, J. Tang, J.H. Zhang, The evolution of molecular hydrogen: a noteworthy potential therapy with clinical significance, Med. Gas Res., 3 (2013) 10.

[2] M. Momirlan, T.N. Veziroglu, The properties of hydrogen as fuel tomorrow in sustainable energy system for a cleaner planet, Int. J. Hydrogen Energy, 30 (2005) 795-802.

[3] R. Ramachandran, R.K. Menon, An overview of industrial uses of hydrogen, Int. J. Hydrogen Energy, 23 (1998) 593-598.

[4] C.-S. Huang, T. Kawamura, Y. Toyoda, A. Nakao, Recent advances in hydrogen research as a therapeutic medical gas, Free Radic. Res., 44 (2010) 971-982.

[5] B. Árnason, T.I. Sigfússon, Iceland-a future hydrogen economy, Int. J. Hydrogen Energy, 25 (2000) 389-394.

[6] M.Z. Jacobson, W.G. Colella, D.M. Golden, Cleaning the air and improving health with hydrogen fuel-cell vehicles, Science, 308 (2005) 1901-1905.

[7] S. Koca, Transition to Hydrogen Fuel Cell Vehicles, Nova Science Publishers2010.

[8] I.P. Jain, Hydrogen the fuel for 21st century, Int. J. Hydrogen Energy, 34 (2009) 7368-7378.

[9] W. Peschka, Liquid hydrogen: fuel of the future, Springer Science \& Business Media2012.

[10] B. Cook, Introduction to fuel cells and hydrogen technology, Eng. Sci. Educ. J., 11 (2002) 205-216.

[11] M. Warshay, P.R. Prokopius, The fuel cell in space: yesterday, today and tomorrow, J. Power Sources, 29 (1990) 193-200.

[12] K.L. Cashdollar, I.A. Zlochower, G.M. Green, R.A. Thomas, M. Hertzberg, Flammability of methane, propane, and hydrogen gases, J. Loss Prev. Process Ind., 13 (2000) 327-340.

[13] W.W. Lace, The Hindenburg Disaster of 1937, Infobase Publishing2008.

[14] R. Saxén, T.K. Taipale, H. Aaltonen, Radioactivity of wet and dry deposition and soil in Finland after the Chernobyl accident in 1986, Finnish Centre for Radiation and Nuclear Safety, 1987.

[15] E.J. Bromet, Mental health of residents near the Three Mile Island reactor: a comparative study of selected groups, J. Prev. Psychiatry, 1 (1982) 225-276.

[16] M. Rogovin, Three Mile Island: A report to the commissioners and to the public, Nuclear Regulatory Commission, Washington, DC (USA), 1979.

[17] K. Buesseler, M. Aoyama, M. Fukasawa, Impacts of the Fukushima nuclear power plants on marine radioactivity, Environ. Sci. Technol., 45 (2011) 9931-9935.

[18] T. Hübert, L. Boon-Brett, G. Black, U. Banach, Hydrogen sensors-a review, Sens. Actuators B Chem., 157 (2011) 329-352.

[19] X. Liu, S. Cheng, H. Liu, S. Hu, D. Zhang, H. Ning, A Survey on Gas Sensing Technology, Sensors, 12 (2012) 96359665.

[20] J.R. Stetter, J. Li, Amperometric Gas Sensors: A Review, Chem. Rev., 108 (2008) 352-366.

[21] M.J. Madou, S.R. Morrison, Chemical sensing with solid state devices, Elsevier2012.

[22] G.F. Fine, L.M. Cavanagh, A. Afonja, R. Binions, Metal Oxide Semi-Conductor Gas Sensors in Environmental Monitoring, Sensors, 10 (2010) 5469-5502.

[23] F. DiMeo, S. Chen, P. Chen, J. Neuner, A. Roerhl, J. Welch, MEMS-based hydrogen gas sensors, Sens. Actuators B - Chem., 117 (2006) 10-16.

[24] A.Z. Sadek, W. Wlodarski, K. Kalantar-Zadeh, C. Baker, R.B. Kaner, Doped and dedoped polyaniline nanofiber based conductometric hydrogen gas sensors, Sens. Actuators A - Phys., 139 (2007) 53-57.

[25] H. Gu, Z. Wang, Y. Hu, Hydrogen gas sensors based on semiconductor oxide nanostructures, Sensors, 12 (2012) 5517-5550.

[26] G. Korotcenkov, S.D. Han, J.R. Stetter, Review of Electrochemical Hydrogen Sensors, Chem. Rev., 109 (2009) 1402-1433.

[27] D.S. Silvester, Recent advances in the use of ionic liquids for electrochemical sensing, Analyst, 136 (2011) 4871-4882.

[28] M.C. Buzzeo, C. Hardacre, R.G. Compton, Use of Room Temperature lonic Liquids in Gas Sensor Design, Anal. Chem., 76 (2004) 4583-4588.

[29] E.I. Rogers, A.M. O'Mahony, L. Aldous, R.G. Compton, Amperometric Gas Detection Using Room Temperature Ionic Liquid Solvents, ECS Trans., 33 (2010) 473-502.

[30] D.S. Silvester, L. Aldous, C. Hardacre, R.G. Compton, An Electrochemical Study of the Oxidation of Hydrogen at Platinum Electrodes in Several Room Temperature lonic Liquids, J. Phys. Chem. B, 111 (2007) 5000-5007. 
[31] D.S. Silvester, K.R. Ward, L. Aldous, C. Hardacre, R.G. Compton, The electrochemical oxidation of hydrogen at activated platinum electrodes in room temperature ionic liquids as solvents, J. Electroanal. Chem., 618 (2008) 5360.

[32] J.A. Bautista-Martinez, L. Tang, J.-P. Belieres, R. Zeller, C.A. Angell, C. Friesen, Hydrogen Redox in Protic lonic Liquids and a Direct Measurement of Proton Thermodynamics, J. Phys. Chem. C, 113 (2009) 12586-12593.

[33] S.E. Goodwin, D.A. Walsh, Hydrogen Electrooxidation under Conditions of High Mass Transport in RoomTemperature Ionic Liquids and the Role of Underpotential Deposited Hydrogen, J. Phys. Chem. C, 120 (2016) 11498-11507.

[34] L. Johnson, A. Ejigu, P. Licence, D.A. Walsh, Hydrogen Oxidation and Oxygen Reduction at Platinum in Protic lonic Liquids, J. Phys. Chem. C, 116 (2012) 18048-18056.

[35] Y. Meng, L. Aldous, R.G. Compton, Electrochemistry of Hydrogen in the Room Temperature lonic Liquid 1Butyl-3-methylimidazolium Bis(trifluoromethylsulfonyl)imide: Dissolved Hydrogen "Lubricates" Diffusional Transport, J. Phys. Chem. C, 115 (2011) 14334-14340.

[36] J.B. Rollins, J.C. Conboy, Kinetics and Thermodynamics of Hydrogen Oxidation and Oxygen Reduction in Hydrophobic Room-Temperature lonic Liquids, J. Electrochem. Soc., 156 (2009) B943-B954.

[37] A.P. Sandoval, M.F. Suarez-Herrera, J.M. Feliu, Hydrogen Redox Reactions in 1-Ethyl-2,3-dimethylimidazolium Bis(trifluoromethylsulfonyl)imide on Platinum Single Crystal Electrodes, Electrochem. Commun., 46 (2014) 84-86. [38] Y. Tang, L. Lin, A. Kumar, M. Guo, M. Sevilla, X. Zeng, Hydrogen Electrooxidation in Ionic Liquids Catalyzed by the NTf2 Radical, J. Phys. Chem. C, 121 (2017) 5161-5167.

[39] Y. Tang, X. Zeng, Electrochemical Oxidation of Hydrogen in Bis(trifluoromethylsulfonyl)imide lonic Liquids under Anaerobic and Aerobic Conditions, J. Phys. Chem. C, 120 (2016) 23542-23551.

[40] G. Hussain, M.V. Sofianos, J. Lee, C. Gibson, C.E. Buckley, D. Silvester, S., Macroporous platinum electrodes for hydrogen oxidation in ionic liquids, Electrochem. Commun., 86 (2018) 43-47.

[41] Y. Tang, J. He, X. Gao, T. Yang, X. Zeng, Continuous Amperometric Hydrogen Gas Sensing in lonic Liquids, Analyst, 143 (2018) 4136-4146.

[42] L.C. Clark JR., R. Wold, D. Granger, Z. Taylor, Continuous Recording of Blood Oxygen Tensions by Polarography, J. Appl. Physiol., 6 (1953) 189-193.

[43] C.A. Gunawan, M. Ge, C. Zhao, Robust and versatile ionic liquid microarrays achieved by microcontact printing, Nat. Commun., 5 (2014) 3744.

[44] M. Ge, G. Hussain, D.B. Hibbert, D.S. Silvester, C. Zhao, lonic Liquid-based Microchannels for Highly Sensitive and Fast Amperometric Detection of Toxic Gases, Electroanalysis, 31 (2019) 66-74.

[45] J. Lee, K. Murugappan, D. Arrigan, W. M., D. Silvester, S., Oxygen reduction voltammetry on platinum macrodisk and screen-printed electrodes in ionic liquids: Reaction of the electrogenerated superoxide species with compounds used in the paste of Pt screen-printed electrodes?, Electrochim. Acta, 101 (2013) 158-168.

[46] A.J. Bard, L.R. Faulkner, Electrochemical Methods: Fundamentals and Applications, John Wiley New York, 2001. [47] J.J. Burk, S.K. Buratto, Electrodeposition of Pt Nanoparticle Catalysts from $\mathrm{H} 2 \mathrm{Pt}(\mathrm{OH}) 6$ and Their Application in PEM Fuel Cells, J. Phys. Chem. C, 117 (2013) 18957-18966.

[48] H. Awada, G. Castlelein, M. Brogly, Quantitative determination of surface energy using atomic force microscopy: The case of Hydrophobic/Hydrophobic contact and hydrophilic/hydrophilic contact, Surf. Interface Anal., 37 (2005) 755-764.

[49] R. Gondosiswanto, D.B. Hibbert, Y. Fang, C. Zhao, Ionic Liquid Microstrips Impregnated with Magnetic Nanostirrers for Sensitive Gas Sensors, ACS Appl. Mater. Interfaces, 9 (2017) 43377-43385.

[50] A.S. Varela, M. Kroschel, T. Reier, P. Strasser, Controlling the selectivity of $\mathrm{CO} 2$ electroreduction on copper: The effect of the electrolyte concentration and the importance of the local pH, Catalysis Today, 260 (2016) 8-13.

[51] D. Himmel, S.K. Goll, F. Scholz, V. Radtke, I. Leito, I. Krossing, Absolute Brønsted Acidities and pH Scales in lonic Liquids, ChemPhysCgem, 16 (2015) 1428-1439.

[52] J. Wandt, J. Lee, D.W.M. Arrigan, D.S. Silvester, A lithium iron phosphate reference electrode for ionic liquid electrolytes, Electrochem. Commun., 93 (2018) 148-151.

[53] D. Silvester, R. Compton, Electrochemical Behaviour of Dissolved Proton Species in Room Temperature lonic Liquids, (2009).

[54] M.C. Buzzeo, O.V. Klymenko, J.D. Wadhawan, C. Hardacre, K.R. Seddon, R.G. Compton, Voltammetry of oxygen in the room-temperature ionic liquids 1-ethyl-3-methylimidazolium bis ((trifluoromethyl) sulfonyl) imide and hexyltriethylammonium bis ((trifluoromethyl) sulfonyl) imide: one-electron reduction to form superoxide. Steadystate and transient behavior in the same cyclic voltammogram resulting from widely different diffusion coefficients of oxygen and superoxide, J. Phys. Chem. A, 107 (2003) 8872-8878. 
[55] R.G. Evans, O.V. Klymenko, S.A. Saddoughi, C. Hardacre, R.G. Compton, Electroreduction of oxygen in a series of room temperature ionic liquids composed of group 15-centered cations and anions, J. Phys. Chem. B, 108 (2004) 7878-7886.

[56] C.L. Bentley, A.M. Bond, A.F. Hollenkamp, P.J. Mahon, J. Zhang, Mass Transport Studies and Hydrogen Evolution at a Platinum Electrode Using Bis(trifluoromethanesulfonyl)imide as the Proton Source in lonic Liquids and Conventional Solvents, J. Phys. Chem. C, 118 (2014) 29663-29673.

[57] I.B. Goldberg, A.J. Bard, S.W. Feldberg, Resistive Effects in Thin Electrochemical Cells: Digital Simulations of Electrochemistry in Electron Spin Resonance Cells, J. Phys. Chem., 76 (1972) 2550-2559.

[58] I. Streeter, G.G. Wildgoose, L. Shao, R.G. Compton, Cyclic voltammetry on electrode surfaces covered with porous layers: An analysis of electron transfer kinetics at single-walled carbon nanotube modified electrodes, Sens. Actuators B - Chem., 133 (2008) 462-466.

[59] M.T. Carter, J.R. Stetter, M.W. Findlay, V. Patel, Printed Amperometric Gas Sensors, ECS Trans., 50 (2012) 211220. 